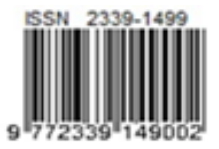

\title{
Analisis Evaluasi Usability Website Universitas Negeri di Karawang Menggunakan Model UWIS
}

\author{
Muhammad Eldo Abdilah', Aulia Hadining ${ }^{2}$, Dene Herwanto ${ }^{3}$ \\ ${ }_{1,2,3)}$ Fakultas Teknik, Jurusan Teknik Industri, Universitas Singaperbangsa Karawang \\ Jl. H.S. Ronggowaluyo Telukjambe Timur, Karawang \\ Email: m.eldoabdillah@gmail.com, aulia.fasha@gmail.com, deneherwanto@yahoo.com
}

\begin{abstract}
Information technology is widely used by tertiary institution. State University in Karawang uses it in the form of a website. The website is the main website in that University of information system managed by Information and Communication Technology Technical Unit (TU ICT). TU ICT plans to develop a new website, it needs to evaluate the old website so that users can use it more easily and satisfactorily. This study aims to identify the influencing factors of usability website University using the UWIS method (usability assessment and design of web-based information systems) as an evaluation material on a new website that will be launched later. Calculations are performed with Partial Least Square (PLS) on SmartPLS 3.0. The results show that there are four diensions that affect the usability of website University which must be considered by parties concerned Consistency (C), Assurance (A), Web Design (WD), and Satisfaction (SF).
\end{abstract}

Keywords: Partial Least Square (PLS), usability assessment, website, web usability

\begin{abstract}
Abstrak
Teknologi informasi semakin banyak digunakan oleh perguruan tinggi. Universitas negeri di Karawang memanfaatkanya dalam bentuk website. Website tersebut merupakan website utama dalam sistem informasi universitas yang dikelola oleh Unit Pelaksana Teknis Teknologi Informasi dan Komunikasi (UPT TIK). UPT TIK berencana akan mengembangkan website baru, perlu dilakukan evaluasi terhadap website lama agar user dapat menggunakannya dengan lebih mudah dan memuaskan. Penelitian ini bertujuan untuk mengidentifikasi faktor-faktor yang mempengaruhi usability website universitas menggunakan metode UWIS (usability assessment and design of web-based information systems) sebagai bahan evaluasi pada website baru yang akan diluncurkan nanti. Perhitungan dilakukan menggunakan Partial Least Square (PLS) pada software SmartPLS 3.0. Hasil penelitian menunjukkan bahwa terdapat empat dimensi yang berpengaruh terhadap web usability website universitas yang harus diperhatikan oleh pihak terkait, yaitu Consistency (C), Assurance (A), Web Design (WD), dan Satisfaction (SF).
\end{abstract}

Kata Kunci: Partial Least Square (PLS), usability assessment, website, web usability;

\section{Pendahuluan}

Kehadiran teknologi informasi berkembang dengan pesat dari waktu ke waktu, terutama di bidang teknologi berbasis internet khususnya website. Perkembangan website yang pesat semakin memudahkan dalam proses penyaluran informasi. Hampir semua organisasi mulai dari perusahaan, lembaga, dan institusi pendidikan membutuhkan sebuah website. Begitu juga institusi pendidikan tinggi membutuhkan website untuk mempermudah mahasiswa dalam memperoleh berbagai macam informasi terkait informasi kuliah (Alfidella, Kusumo, \& Suwawi, 2015).

Pelayanan informasi yang berkualitas merupakan suatu tuntutan yang harus disediakan oleh pihak universitas terhadap penggunanya. Penerapan layanan website perguruan tinggi bertujuan untuk menciptakan kepuasan para penggunanya (Kesuma, 2014).

Usability adalah kemampuan suatu sistem untuk memberi kemudahan bagi pengguna, efektif dan efisien dalam mencapai suatu tujuan untuk mencapai kepuasan (Hermanto, 2017). Sedangkan, menurut ISO 9241 Part 11, usability mengacu kepada 
seberapa efektif, efisien, dan memuaskannya suatu produk saat digunakan oleh pengguna untuk mencapai tujuan spesifik dalam konteks penggunaan (Bevan \& Carter, 2016). Konteks penggunaan yang dimaksud terdiri dari pengguna, hardware, software, material, dan lingkungan fisik serta sosial yang mempengaruhi usability produk dalam sistem kerja (Bevan \& Carter, 2016).

Menurut Ketua UPT TIK universitas pada tahun ini pihaknya akan mengembangkan website baru. Perlu adanya upaya untuk mengevaluasi website lama untuk dilakukan perbaikan pada website baru yang akan dibuat. Dibutuhkan adanya suatu penelitian yang memfokuskan pada permasalahanpermasalahan yang sering dialami oleh user website universitas terutama yang terkait dengan perspektif user. Salah satu cara untuk menilai suatu kualitas website adalah dengan melakukan penilaian tingkat usability dari suatu website.

Hal tersebut bertujuan agar website baru yang diluncurkan nanti sesuai dengan harapan dan kebutuhan user. Pengembang website bisa saja menciptakan berbagai fasilitas tertentu, tetapi belum tentu dibutuhkan oleh user. Maka, perlu dilakukan pengukuran kemampugunaan (usability) website universitas menurut perspektif user. Penelitian ini bertujuan untuk mengidentifikasi factor-faktor yang mempengaruhi secara signifikan terhadap usability website universitas.

\section{Metode Penelitian}

Model Penelitian

An assessment methodology for usability of web-based information systems (UWIS) merupakan model dasar yang diperkenalkan oleh Oztekin et al. (2009) untuk mengevaluasi usabilitas website dengan mengintegrasikan antara dimensi kualitas (ServQual dan Webbased Service Quality) dan dimensi usabilitas (Usability Heuristics dan ISO 9241-10).

Penelitian lain yang berkaitan dengan model UWIS telah banyak dilakukan. Aisha et al. (2015) menggunakan metode UWIS untuk menilai website sistem informasi i-caring di Telkom University dengan hasil penelitian yang menyatakan bahwa model UWIS Oztekin et al. (2009) kurang memperhatikan dimensi antarmuka yang kemudian dikembangkan dengan menambahkan beberapa variabel yaitu consistency, simplicity, readability, dan web design. Penelitian Herwanto et al. (2018) menggunakan metode UWIS dengan mendapatkan hasil bahwa responsiveness, web design, assurance, readability, dan navigation perlu diperhatikan sebagai bahan evaluasi untuk perbaikan pada Sistem Informasi Akademik (SIAKAD) Fakultas Teknik universitas.

Penelitian ini menggunakan metode UWIS untuk mengukur tingkat usability website universitas. Model yang digunakan mengacu kepada model penelitian yang dikembangkan oleh Aisha et al. (2015). Model penelitian ini ditunjukkan oleh Gambar 1. Masing-masing variabel dijelaskan pada Tabel 1.

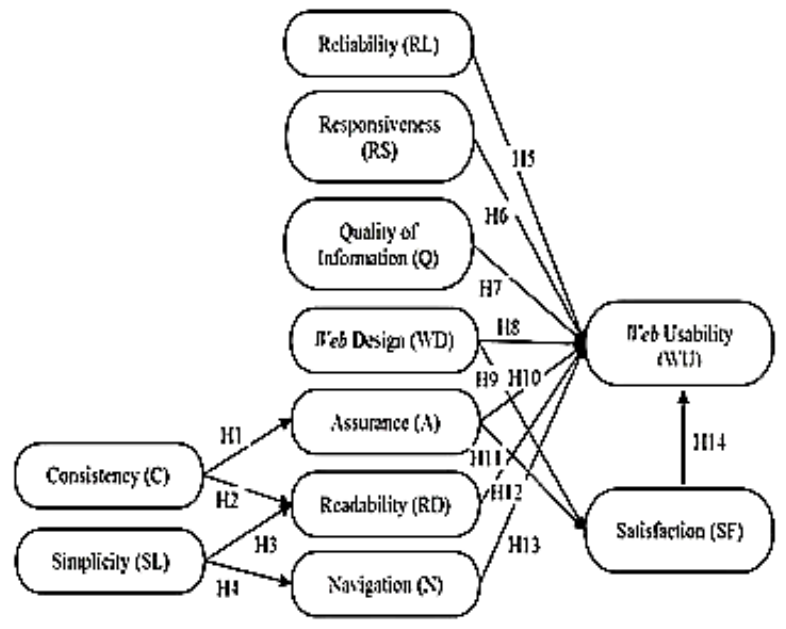

Gambar 1. Model Penelitian

Sumber: Aisha et al. (2015)

Tabel 1 Variabel Penelitian

\begin{tabular}{|c|l|}
\hline Variabel & \multicolumn{1}{|c|}{ Definisi } \\
\hline Assurance (A) & $\begin{array}{l}\text { Kemampuan untuk } \\
\text { memberi kepercayaan } \\
\text { dan rasa aman }\end{array}$ \\
\hline Consictency (C) & $\begin{array}{l}\text { Letak komponen } \\
\text { halaman, konsistensi } \\
\text { seluruh halaman }\end{array}$ \\
\hline Navigation (N) & $\begin{array}{l}\text { Memberitahukan kepada } \\
\text { user posisi terakhir } \\
\text { mereka ketika berada } \\
\text { dalam sautu website } \\
\text { sehingga tidak tersesat } \\
\text { saat menjelajah }\end{array}$ \\
\hline Quality of & $\begin{array}{l}\text { Kemampuan website } \\
\text { dalam menyediakan } \\
\text { informasi yang mudah } \\
\text { dipahami, relevan } \\
\text { dengan konten yang } \\
\text { lengkap dan informasi } \\
\text { yang aman bagi user }\end{array}$ \\
\hline Readability (RD) & $\begin{array}{l}\text { Sejauh mana komponen } \\
\text { website terorganisir } \\
\text { dengan baik sehingga }\end{array}$ \\
\hline
\end{tabular}




\begin{tabular}{|c|c|}
\hline Variabel & Definisi \\
\hline & $\begin{array}{l}\text { mudah dibaca dan } \\
\text { dipahami }\end{array}$ \\
\hline Reliability $(\mathrm{RL})$ & $\begin{array}{l}\text { Layanan yang dapat } \\
\text { diandalkan dan akurat }\end{array}$ \\
\hline $\begin{array}{c}\text { Responsiveness } \\
\text { (RS) }\end{array}$ & $\begin{array}{l}\text { Layanan untuk } \\
\text { membantu user dan } \\
\text { memberikan layanan } \\
\text { yang cepat }\end{array}$ \\
\hline $\begin{array}{l}\text { Satisfaction } \\
\quad \text { (SF) }\end{array}$ & $\begin{array}{l}\text { Persepsi pengguna } \\
\text { ketika membandingkan } \\
\text { harapan suatu produk } \\
\text { dengan hal nyata yang } \\
\text { dialami ketika } \\
\text { menggunakan produk } \\
\text { atau pelayanan } \\
\end{array}$ \\
\hline Simplicity (SL) & $\begin{array}{l}\text { Menyediakan konten dan } \\
\text { fungsi seminimum } \\
\text { mungkin dalam website }\end{array}$ \\
\hline $\begin{array}{l}\text { Web Design } \\
\text { (WD) }\end{array}$ & $\begin{array}{l}\text { Menjelaskan tentang tata } \\
\text { letak penempatan baik } \\
\text { menu, ikon, navigasi, } \\
\text { maupun warna yang } \\
\text { digunakan dalam } \\
\text { merancang website }\end{array}$ \\
\hline $\begin{array}{l}\text { Web Usability } \\
\text { (WU) }\end{array}$ & $\begin{array}{l}\text { Tingkat sebuah produk } \\
\text { yang dapat digunakan } \\
\text { oleh pengguna tertentu } \\
\text { untuk mencapai tujuan } \\
\text { spesifik dengan efektif, } \\
\text { efisien, dan memuaskan } \\
\text { dalam sebuah konteks } \\
\text { penggunaan }\end{array}$ \\
\hline
\end{tabular}

Sumber : (Bevan \& Carter, 2016; Delone \& Mclean, 2003; Kotler, 2002; Krug, 2013; Lee \& Kozar, 2012; Parasuraman, et al., 1988)

\section{Tahapan penelitian}

Pengujian usability menggunakan metode eksperimen dan kuesioner. Pengujian melibatkan mahasiswa universitas dari semua program studi sebanyak seratus orang sebagai sampel. Kuesioner yang digunakan yaitu Usability Assessment for Usability Web-based Informaion Systems (UWIS). Kuesioner UWIS ditunjukkan pada Tabel 2. Uji eksperimen dilakukan melalui beberapa penugasan (task) yang diadopsi dari penelitian Oztekin et al. (2009) berikut:

Task 1: Melihat tampilan dan merubah bahasa website.
Task 2: Melihat nilai akreditasi program studi.

Task 3: Mencari kontak informasi pada website.

Task 4: Mengirim pesan pada email yang tersedia pada kontak informasi.

Usability mengukur tingkat efektivitas, efisiensi dan kepuasan user. Efektivitas diukur dari seberapa mudah user dalam mengerjakan tugas (task) yang diberikan. Efisiensi dilihat melalui seberapa cepat user dalam menyelesaikan tugas yang diberikan. Banyak responden mengeluhkan tugas yang diberikan cukup sulit sehingga waktu pengerjaan tugas cukup lama. Perhitungan efektivitas dan efisiensi belum dapat dilakukan seperti pada penelitian Oztekin et al (2009) karena dalam pengerjaan tugas setiap responden tidak pada waktu dan tempat yang sama serta menggunakan akses internet yang berbeda. Penelitian ini lebih memfokuskan pada pengukuran kepuasan melalui kuesioner UWIS terhadap website universitas (Herwanto et al., 2018).

Berdasarkan Gambar 2, maka hipotesis penelitian yang dapat diajukan yaitu sebagai berikut (Aisha et al., 2015):

a) Hipotesis $1:$ Ada hubungan yang signifikan antara consistency dan assurance.

b) Hipotesis 2 : Ada hubungan yang signifikan antara consistency dan readability.

c) Hipotesis 3: Ada hubungan yang signifikan antara simplicity dan readability.

d) Hipotesis 4: Ada hubungan yang signifikan antara simplicity dan navigation.

e) Hipotesis 5: Ada pengaruh yang signifikan dari reliability terhadap web usability.

f) Hipotesis 6: Ada pengaruh yang signifikan dari responsiveness terhadap web usability.

g) Hipotesis 7: Ada pengaruh yang signifikan dari information quality terhadap web usability.

h) Hipotesis 8: Ada pengaruh yang signifikan dari web design terhadap web usability.

i) Hipotesis 9: Ada hubungan yang signifikan antara web design dan satisfaction.

j) Hipotesis 10: Ada pengaruh yang signifikan dari assurance terhadap web usability. 
k) Hipotesis 11: Ada hubungan yang signifikan antara assurance dan satisfaction.

I) Hipotesis 12: Ada pengaruh yang signifikan dari readability terhadap web usability.

m) Hipotesis 13: Ada pengaruh yang signifikan dari navigation terhadap web usability.

n) Hipotesis 14: Ada pengaruh yang signifikan dari satisfaction terhadap web usability.

\section{Hasil Penelitian}

Data yang diperlukan yaitu pendapat dari user yang dijadikan sebagai responden terhadap kemampugunaan (usability) website universitas sebanyak 100 (seratus). Responden yang dipilih merupakan mahasiswa universitas yang telah menempuh minimal pendidikan selama satu semester perkuliahan di universitas, dan dipilih berdasarkan proporsional purposive sampling. Responden yang terpilih akan diminta untuk mengisi kuesioner yang telah disiapkan. Akan tetapi, sebelum mengisi kuesioner responden diminta untuk melaksanakan empat tugas yang telah dijelaskan pada uraian sebelumnya. Hal ini bertujuan untuk melihat seberapa mudah dan cepat responden dalam mengerjakan tugas tersebut sebelum menjawab kuesioner.

Data hasil kuesioner yang telah terkumpul diolah menggunakan teknik perhitungan Partial Least Square (PLS) dengan software SmartPLS 3.0. Hasil data ini akan digunakan sebagai bahan masukan bagi pihak pengembang (UPT TIK) dalam merancang website baru. Pembuatan model penelitian pada SmartPLS 3.0 dapat dilihat pada Gambar 3.

Pengolahan data pada PLS terbagi menjadi dua tahapan, yaitu dengan penilaian model pengukuran dan evaluasi model struktural. Model pengukuran dinilai melalui beberapa indikator seperti validitas konvergen, validitas diskriminan, dan uji reliabilitas. Evaluasi model struktural dinilai berdasarkan nilai $\mathrm{R}^{2}$ dan koefisien jalur.

\section{Penilaian Model Pengukuran}

Pada tahap ini dilakukan uji validitas dan uji reliabilitas terhadap variabel laten sebagai model yang digunakan pada penelitian. Validitas konvergen dapat dilihat pada Tabel 2.

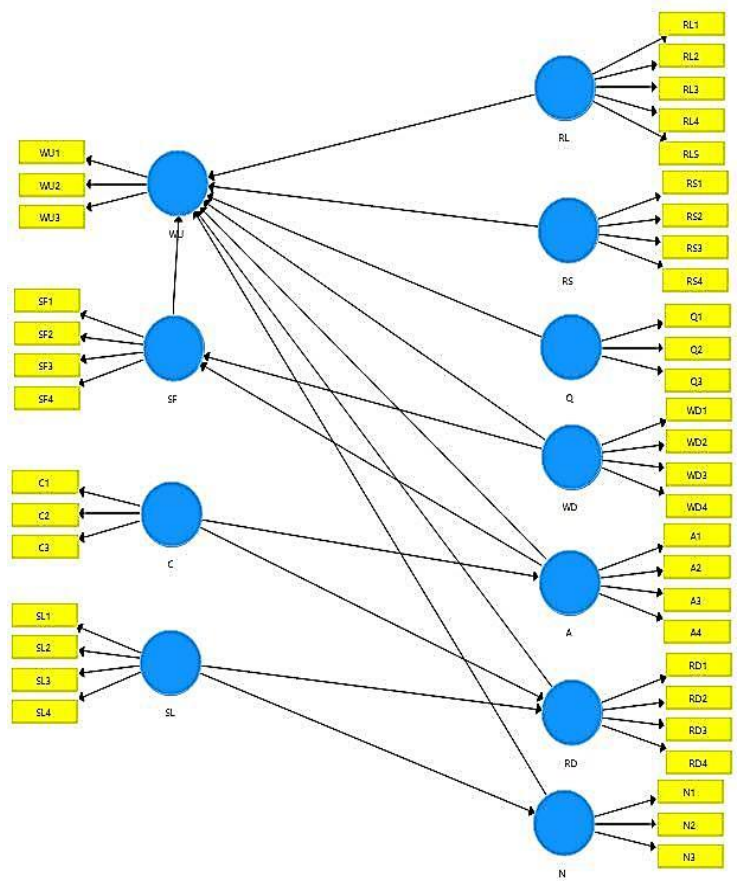

Gambar 3. Pembuatan Model Penelitian

Berdasarkan Tabel 2, diketahui bahwa nilai hampir seluruh indikator memilki loading factors $>0.5$ dan dikatakan valid konvergen (Ghozali, 2014). Uji validitas diskriminan dinilai melalui Average Variance Extracted (AVE)> 0.5. Uji Reliabilitas dinilai melalui reliability composite $>0.7$. Cronbach's alpha $>0.7$ dapat dikatakan memiliki reliabilitas kuat (Ghozali, 2014). Uji validitas diskriminan dan uji reliabilitas dapat dilihat pada Tabel 3.

Tabel 3 Validitas Diskriminan dan Reliabilitas

\begin{tabular}{|c|c|c|c|c|}
\hline $\begin{array}{c}\text { Variabe } \\
\text { I }\end{array}$ & AVE & $\begin{array}{c}\text { Composite } \\
\text { Realiabilit } \\
\mathbf{y}\end{array}$ & $\begin{array}{c}\text { Conbach's } \\
\text { Alpha }\end{array}$ & R2 \\
\hline A & 0.519 & 0.757 & 0.524 & 0.267 \\
\hline C & 0.585 & 0.806 & 0.654 & \\
\hline N & 0.5 & 0.741 & 0.507 & 0.151 \\
\hline Q & 0.585 & 0.807 & 0.639 & \\
\hline RD & 0.58 & 0.846 & 0.757 & 0.354 \\
\hline RL & 0.55 & 0.827 & 0.721 & \\
\hline RS & 0.566 & 0.838 & 0.744 & \\
\hline SF & 0.744 & 0.932 & 0.901 & 0.678 \\
\hline SL & 0.662 & 0.887 & 0.83 & \\
\hline WD & 0.576 & 0.843 & 0.75 & \\
\hline WU & 0.73 & 0.89 & 0.816 & 0.668 \\
\hline
\end{tabular}

Berdasarkan Tabel 3 dapat dilihat bahwa nilai AVE setiap variabel laten sudah melebihi angka 
0.5 , dapat dikatakan seluruh variabel laten telah lulus uji validitas diskriminan. Nilai composite reliability untuk setiap variabel sudah melebihi angka 0.7 , maka setiap variabel sudah reliabel. Nilai cronbach's alpha beberapa variabel melebihi angka 0.7 yang menandakan bahwa variabel tersebut memiliki reliabilitas yang kuat (Guildford, 1956).

\section{Evaluasi Model Struktural}

Evaluasi model struktural dilakukan dengan melihat nilai $\mathrm{T}$ statistik untuk menguji signifikasi model struktural. Analisis lain yang diperlukan yaitu analisis inner model dengan indikator $\mathrm{R}^{2}$ yang menunjukkan tingkat variabilitas pada setiap variabel endogen yang dipengaruhi oleh variabel lain.

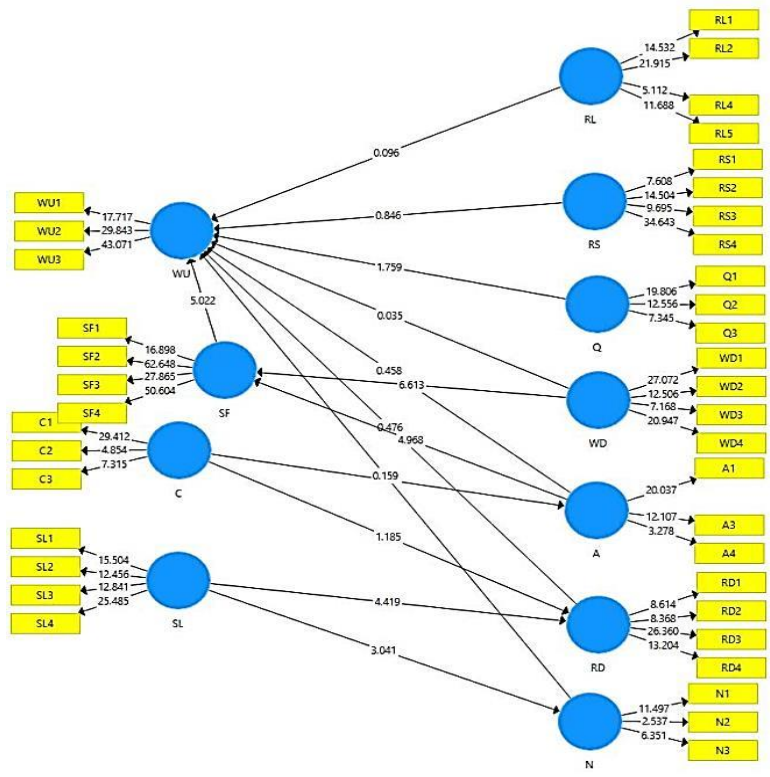

Gambar 4. Path Model

Berdasarkan Tabel 2, dapat dilihat bahwa:

a. Consistency menerangkan $26.7 \%$ dari varians dalam assurance.

b. Simplicity dan consistency bersama-sama menerangkan $35.4 \%$ varians dalam readability.

c. Simplicity hanya menerangkan sebesar $15.1 \%$ varians dalam navigation.

d. Web design dan assurance menerangkan $67.8 \%$ varians dalam satisfaction.

e. Varians dalam web usability (WU) sebesar $66,8 \%$ diterangkan oleh variabelvariabel seperti reliability, responsiveness, quality of information, web design, assurance, readability, navigation, dan satisfaction.

Hasil tersebut memperlihatkan banyak variabel yang mempengaruhi web usability secara signifikan. Namun, belum diketahui pasti variabel mana yang memiliki dampak paling signifikan untuk menguji hipotesis penelitian. Hipotesis diuji dengan mengevaluasi path coefficient pada inner model. Dengan uji t statistik menggunakan tingkat signifikasi $5 \%$, path coefficient akan signifikan jika nilai $\mathrm{t}$ statistik melebihi 1.96. Hasil uji hipotesis dapat dilihat pada Tabel 3

\section{Hasil dan Pembahasan}

Tujuan dari penelitian ini adalah untuk mengetahui hubungan antar faktor web usability pada website universitas dan faktor mana yang berpengaruh signifikan terhadap usability website universitas. Tujuan lainnya yaitu untuk mengetahui dimensi mana saja yang perlu diperbaiki pada website universitas saat ini menurut perspektif user agar pada website baru nanti permasalahan yang sama tidak terulang kembali. Menurut pernyataan UPT TIK, saat ini pihaknya sedang mengembangkan website baru universitas sebagai pengganti website universitas saat ini karena dirasa kurang handal.

User perlu dilibatkan dalam pengembangan website tersebut agar kelak website universitas mudah digunakan dan memberikan kepuasan terhadap user karena dikembangkan menurut kebutuhannya.

Dimensi yang menjadi perhatian user diperoleh melalui identifikasi faktor yang mempengaruhi web usability website universitas. Berdasarkan pengolahan data dimensi tersebut yaitu, Consistency (C), Simplicity(SL), Web Design (WD), Assurance (A), Satisfaction (SF).

Dimensi Consistency (C) memiliki pengaruh yang signifikan terhadap Assurance (A). Hasil tersebut sesuai dengan penelitian Aisha et al. (2015) yang menyatakan bahwa konsistensi tata letak komponen dan menu antar halaman dalam website akan memudahkan pengguna dalam menggunakan website. Kondisi ini mendukung pemahaman informasi dan mempelajari situs web yang diakses (Lee \& Kozar, 2012). Consistency website yang baik membuat user merasa tenang menjelajah di website universitas. Misalnya, ketika user mengeksplorasi website tidak perlu merasa khawatir tersesat karena struktur, komponen, dan tampilan antar halaman website sama antar halaman dan tersedia fasilitas home untuk kembali ke halaman beranda. 
DOI: https://doi.org/10.26593/jrsi.v8i2.3305.89-98

Tabel 2 Loading Factors

\begin{tabular}{|c|c|c|c|c|c|c|c|c|c|c|c|}
\hline & A & C & $\mathbf{N}$ & $\mathbf{Q}$ & RD & $\mathbf{R L}$ & RS & SF & SL & WD & WU \\
\hline A1 & 0.833 & & & & & & & & & & \\
\hline A2 & 0.470 & & & & & & & & & & \\
\hline A3 & 0.763 & & & & & & & & & & \\
\hline C1 & & 0.897 & & & & & & & & & \\
\hline C2 & & 0.663 & & & & & & & & & \\
\hline C3 & & 0.715 & & & & & & & & & \\
\hline N1 & & & 0.826 & & & & & & & & \\
\hline N2 & & & 0.517 & & & & & & & & \\
\hline N3 & & & 0.736 & & & & & & & & \\
\hline Q1 & & & & 0.850 & & & & & & & \\
\hline Q2 & & & & 0.759 & & & & & & & \\
\hline Q3 & & & & 0.677 & & & & & & & \\
\hline RD1 & & & & & 0.722 & & & & & & \\
\hline RD2 & & & & & 0.693 & & & & & & \\
\hline RD3 & & & & & 0.859 & & & & & & \\
\hline RD4 & & & & & 0.762 & & & & & & \\
\hline RL1 & & & & & & 0.769 & & & & & \\
\hline RL2 & & & & & & 0.825 & & & & & \\
\hline RL3 & & & & & & 0.434 & & & & & \\
\hline RL4 & & & & & & 0.588 & & & & & \\
\hline RL5 & & & & & & 0.722 & & & & & \\
\hline RS1 & & & & & & & 0.654 & & & & \\
\hline RS2 & & & & & & & 0.798 & & & & \\
\hline RS3 & & & & & & & 0.709 & & & & \\
\hline RS4 & & & & & & & 0.836 & & & & \\
\hline SF1 & & & & & & & & 0.795 & & & \\
\hline SF2 & & & & & & & & 0.931 & & & \\
\hline SF3 & & & & & & & & 0.870 & & & \\
\hline SF4 & & & & & & & & 0.917 & & & \\
\hline SL1 & & & & & & & & & 0.799 & & \\
\hline SL2 & & & & & & & & & 0.797 & & \\
\hline SL3 & & & & & & & & & 0.789 & & \\
\hline SL4 & & & & & & & & & 0.867 & & \\
\hline WD1 & & & & & & & & & & 0.838 & \\
\hline WD2 & & & & & & & & & & 0.754 & \\
\hline WD3 & & & & & & & & & & 0.622 & \\
\hline WD4 & & & & & & & & & & 0.804 & \\
\hline WU1 & & & & & & & & & & & 0.819 \\
\hline WU2 & & & & & & & & & & & 0.866 \\
\hline WU3 & & & & & & & & & & & 0.878 \\
\hline
\end{tabular}


DOI: https://doi.org/10.26593/jrsi.v8i2.3305.89-98

Tabel 3 Uji Hipotesis

\begin{tabular}{|c|c|c|c|c|c|c|}
\hline Hipotesis & $\begin{array}{l}\text { Latent } \\
\text { Variabel }\end{array}$ & $\begin{array}{c}\text { Original } \\
\text { Sample (0) }\end{array}$ & $\begin{array}{c}\text { Standard } \\
\text { Error } \\
\text { (STERR) }\end{array}$ & $\begin{array}{c}\text { T Statistic } \\
(\mid \text { O/STERR } \mid)\end{array}$ & P Values & Supported \\
\hline H1 & $C \rightarrow A$ & 0.517 & 0.082 & 6.319 & 0 & Yes \\
\hline $\mathrm{H} 2$ & $C->\mathrm{RD}$ & 0.133 & 0.112 & 1.185 & 0.236 & No \\
\hline H3 & SL -> RD & 0.504 & 0.114 & 4.419 & 0 & Yes \\
\hline $\mathrm{H} 4$ & $S L->N$ & 0.388 & 0.128 & 3.041 & 0.002 & Yes \\
\hline H5 & $\mathrm{RL}->\mathrm{WU}$ & 0.011 & 0.115 & 0.096 & 0.923 & No \\
\hline $\mathrm{H} 6$ & $R S->W U$ & 0.105 & 0.124 & 0.846 & 0.398 & No \\
\hline $\mathrm{H} 7$ & Q -> WU & 0.185 & 0.105 & 1.759 & 0.079 & No \\
\hline $\mathrm{H} 8$ & WD $->$ WU & 0.004 & 0.113 & 0.035 & 0.972 & No \\
\hline $\mathrm{H} 9$ & WD -> SF & 0.492 & 0.074 & 6.613 & 0 & Yes \\
\hline H10 & $A \rightarrow W U$ & 0.049 & 0.106 & 0.458 & 0 & No \\
\hline H11 & A $->S F$ & 0.413 & 0.063 & 4.968 & 0.647 & Yes \\
\hline H12 & RD $->$ WU & -0.038 & 0.079 & 0.476 & 0.635 & No \\
\hline H13 & $\mathrm{N}->\mathrm{WU}$ & -0.014 & 0.089 & 0.159 & 0.874 & No \\
\hline H14 & $S F->W U$ & 0.585 & 0.116 & 5.022 & 0 & Yes \\
\hline
\end{tabular}

Dimensi Simplicity (SL) memiliki pengaruh yang signifikan tehadap Readability (RD) dan Navigation (N). Hasil tersebut sesuai dengan penelititan Aisha et al. (2015) yang menyatakan bahwa simplicity merupakan penyederhanaan konten tampilan dan fungsionalitas pada website. Semakin mudah konten untuk dilihat, maka informasi yang diberikan akan lebih mudah untuk dipahami. Aisha et al. (2015) menyatakan jika navigasi dalam website mudah digunakan, maka pengalaman user akan bertambah. Proses yang jauh lebih mudah akan membuat waktu akses sistem menjadi jauh lebih cepat, karena informasi dapat dengan mudah ditemukan oleh pengguna.

Dimensi Web Design (WD) memiliki pengaruh yang signifikan terhadap Satisfaction (SF). Hasil tersebut sesuai dengan penelititan Aisha et al. (2015) yang menyatakan bahwa fitur dan kelengkapan komponen serta kemudahan mengakses dan penggunaan website akan sangat berpengaruh terhadap kepuasan pengguna situs web. Semakin baik dan menarik web design dari website Universitas akan memberikan kepuasan bagi user. Begitu pula sebaliknya, bila web design yang diupayakan hanya biasa-biasa saja dan kurang menarik cenderung membuat kepuasan user berkurang ketika menjelajah di website. User merasa web design pada website universitas penting untuk meningkatkan kepuasan mereka dalam menjelajah website. User mengharapkan adanya pengembangan dalam web design untuk menujang kepuasan mereka. Beberapa contoh yang menarik versi Webometrics seperti yang dimiliki oleh National University of Singapore (terbaik 1 Asia Tenggara) dan universitas Gajah Mada (terbaik 1 Indonesia).

Dimensi Assurance (A) memiliki pengaruh yang signifikan terhadap Satisfaction (SF). Hasil tersebut sesuai dengan penelititan Aisha et al. (2015) yang menyatakan bahwa user website yang merasa nyaman menggunakan website akan bersedia untuk menggunakan website kembali. Hal ini sangat penting, karena website universitas dibuat untuk mendukung kebutuhan informasi kampus. Apabila sebuah website dapat membuat user merasa nyaman, maka akan sangat berpengaruh terhadap kepuasan user itu sendiri. Elemen-elemen assurance yang dioptimalkan akan membuat user nyaman, dan apabila user merasa nyaman mereka akan merasa puas ketika menjelajah website universitas. User merasa assurance penting dan perlu ditingkatkan kembali seperti memberikan pernyataan keamaan kepada user apabila mereka mengakses website, dan 
tentunya memberikan kemudahan bagi user dengan adanya website universitas. Keamanan pada website universitas masih diragukan, terlihat ketika user mengakses website melalui handphone terdapat peringatan keamanan.

Dimensi Satisfaction (SF) memiliki pengaruh signifikan terhadap Web Usability (WU) dan satu-satunya yang berpengaruh signifikan secara langsung terhadap usability website universitas. Hasil tersebut sesuai dengan penelitian Aisha et al. (2015) yang menyatakan bahwa tingkat kepuasan terhadap penggunaan website akan sangat mempengaruhi penilaian usability. Salah satu indikator dalam mengukur usability adalah kepuasan pengguna saat menggunakan sistem. Oleh karena itu, perlu untuk meningkatkan kualitas layanan website untuk meningkatkan pengalaman pengguna dan kepuasan pengguna website, sehingga user akan bersedia untuk menggunakan website kembali di lain waktu. Hasil ini sesuai dengan pengaruh satisfaction terhadap web usabiiity yang berpengaruh positif dan bepengaruh secara signifikan. User merasa variabel kepuasan ini sangat penting terhadap web usability. Semakin tinggi kepuasan yang diperoleh user ketika menggunakan website, akan meningkatkan web usability website universitas. Perlu adanya upaya pengembangan kembali untuk mencapai hal tersebut seperti menambahkan beberapa layanan untuk membantu kebutuhan user, meningkatkan tampilan website menjadi lebih menarik di setiap halamannya dan menambahkan fitur-fitur baru yang ada pada website universitas untuk mempermudah tugas user.

Berdasarkan uarain tersebut, maka pihak pengembang website universitas perlu memperhatikan hal-hal yang berkaitan dengan kelima faktor atau dimensi tersebut agar menjadi salah satu fokus evaluasi pada website baru.

\section{Simpulan}

Beberapa faktor mempengaruhi
Usability website universitas yang mana
terdapat lima faktor yang paling dominan
daripada faktor lain, yaitu Consistency (C),
Simplicity (SL), Web Design (WD), Assurance

(A), dan Satisfaction (SF). Maka, yang perlu menjadi fokus perhatian pengembang sebagai bahan evaluasi adalah dengan melakukan perbaikan terhadap hal-hal yang berpengarh terhadap kelima dimensi atau faktor tersebut.

\section{Ucapan Terima Kasih}

Ucapan terima kasih yang sebesarbesarnya penulis sampaikan kepada kedua dosen pembimbing yang sangat membantu menyelesaikan paper ini. Begitu pula terimakasih yang sebesar-besarnya kepada pihak UPT TIK atas kesempatan yang diberikan kepada penulis untuk melaksanakan penelitian ini

\section{Daftar Pustaka}

Aisha, A. N., Hadining, A. F., \& Andreswari, R. (2015). Evaluating the usability of academic information system websites. Journal of Scientific Research and Development, 2(13), 151-157. Retrieved from www.jsrad.org

Alfidella, S., Kusumo, D. S., \& Suwawi, D. D. J. (2015). Pengukuran Usability I-Caring Berbasis ISO 9241-11 Dengan Menggunakan Partial Least Square (PLS). EProceedings of Engineering, 2(1), 17471735.

Bevan, N., \& Carter, J. (2016). New ISO Standards for Usability, Usability Reports and Usability Measures (July). https://doi.org/10.1007/978-3-319-395104.

Delone, W. H., \& Mclean, E. R. (2003). The DeLone and McLean Model of Information Systems Success: A Ten-Year Update. Journal of Management Information Systems, 19(4), 9-30.

Ghozali, I. (2014). Structural Equation Modelling: Metode Alternatif Dengan Partial Least Squares (PLS) (Edisi 4). Semarang.

Guildford, B. F. (1956). Fundamental statistics in psychology and education. New York: McGraw-Hill Book.

Hermanto, A. (2017). Evaluasi Usabilitas Layanan Sistem Informasi Akademik Berdasarkan Kombinasi ServQual dan Webqual, (April). https://doi.org/10.20473/jisebi.3.1.33-39

Herwanto, D., Hadining, A. F., \& Sari, R. P. (2018). Analisis Evaluasi Website Sistem Akademik Fakultas Teknik Universitas dengan Model UWIS. Journal of Scientific Research and Development, 2(1), 30-38.

Kesuma, D. P. (2014). Analisis Pengukuran 
DOI: https://doi.org/10.26593/jrsi.v8i2.3305.89-98

Kualitas Layanan Web Perguruan Tinggi XYZ Menggunakan Servqual, 178-183.

Kotler, P. (2002). Marketing Management. New Jersey: Prentice Hall.

Krug, S. (2013). Don't Make Me Think: Panduan Praktis Membangun Web yang Logis (Kedua). Jakarta: PT Serambi Ilmu Semesta.

Lee, Y., \& Kozar, K. A. (2012). Understanding of website usability: Specifying and measuring constructs and their relationships. Decision Support Systems, 52,450-452. https://doi.org/10.1016/j.dss.2011.10.004.

Oztekin, A., Nikov, A., \& Zaim, S. (2009). The Journal of Systems and Software UWIS: An assessment methodology for usability of web-based information systems. The Journal of Systems \& Software, 82(12), 2038-2050.

https://doi.org/10.1016/j.jss.2009.06.047

Parasuraman, A., Zeithmail, V. A., \& Berry, L. (1988). $\quad$ SERVQUAL-A-multiple-ItemScale-for-measuring-consumerperceptions-of-service-quality.pdf. 
DOI: https://doi.org/10.26593/jrsi.v8i2.3305.89-98

Halaman ini sengaja dikosongkan This page is intentionally left blank 